Portland State University

PDXScholar

$7-23-2020$

\title{
Correctional Quackery: a Study of Program Availability and Inmate Assaults in Adult Correctional Facilities
}

Casey Jay Legere

Portland State University

Follow this and additional works at: https://pdxscholar.library.pdx.edu/open_access_etds

Part of the Criminology and Criminal Justice Commons Let us know how access to this document benefits you.

Recommended Citation

Legere, Casey Jay, "Correctional Quackery: a Study of Program Availability and Inmate Assaults in Adult Correctional Facilities" (2020). Dissertations and Theses. Paper 5530.

https://doi.org/10.15760/etd.7404

This Thesis is brought to you for free and open access. It has been accepted for inclusion in Dissertations and Theses by an authorized administrator of PDXScholar. Please contact us if we can make this document more accessible: pdxscholar@pdx.edu. 


\title{
Correctional Quackery:
}

A Study of Program Availability and Inmate Assaults in Adult Correctional Facilities

by

Casey Jay Legere

A thesis submitted in partial fulfillment of the requirements for the degree of

\author{
Master of Science \\ in \\ Criminology and Criminal Justice
}

Thesis Committee:

Christopher M. Campbell, Chair

Kris R. Henning

Mauri Matsuda

Portland State University

2020 


\begin{abstract}
A wide variety of correctional programs have incited a debate regarding the utility and worth of programs within the correctional system. For some, programs are assigned strict qualifications and this narrow focus limits those that are "worthy"; all else are "correctional quackery." These harsh limitations do not allow for the consideration of secondary outcomes as measurements of value. Using negative binomial regression, this study examines 449 state correctional facilities to consider associations between program availability (categorized as correctional quackery or not) and incidence rates of violent assaults among inmates. The minimal significant results yield inconclusive findings but do offer some possible insights for programs negatively associated with inmate-inmate assaults. Considerations for future research and implications are discussed.
\end{abstract}




\section{Dedication}

I dedicate this thesis to my parents Stacey and Steve Legere.

In my second-grade class we had the opportunity to write short stories and then have them professionally bound. I wrote about my new cat and on the dedication page, I wrote a friend's name. Many years later while cleaning out my childhood room I found that book; when I showed it to you both, you said with fake offense, "You didn't dedicate it to us?!" This thesis may not demonstrate my artistic renderings of a cat playing with string, but I think this is much better.

I would not be where I am today without the encouragement and guidance of my parents. You instilled in me the significance of education and a constant desire to learn. Mom, your kindness and generosity constantly inspire me to be a better person. Dad, thank you for always taking the time to teach me important adult skills like writing a resume and planning for travel.

Your belief in me when I did not always believe in myself and unwavering support is the reason for where I am today. Thank you.

I also dedicate this to my nanny and grandpa. Nanny, you've taught me to slow down and appreciate the simple things in life like the new flower blooms on your neighbors' plants. Plus, years of card games have given me quite the arsenal of creative expletives! Grandpa, because of your endless pranks I know that just because I'm getting older doesn't mean I can't have fun. Thank you both for your love and support. 


\section{Acknowledgements}

First, this paper would not be possible without my advisor Christopher $\mathrm{M}$. Campbell. His course on community corrections and prior research inspired my interest in this topic. Thank you for always being willing to answer my questions and help me through statistical coding issues no matter how basic they are. And more than anything, thank you for the encouragement and believing in me when it was difficult for me to do so myself.

I would also like to thank my committee members Kris R. Henning and Mauri Matsuda for taking the time to read my paper and provide invaluable suggestions that contributed significant improvements.

A very special thanks to my friends for curbing my imposter syndrome, giving advice, validating my worth, and continued encouragement. In addition, a big thank you to the 2020 Criminology and Criminal Justice cohort for their pep talks, vent sessions, and the immense amount of statistics guidance. 


\section{Table of Contents}

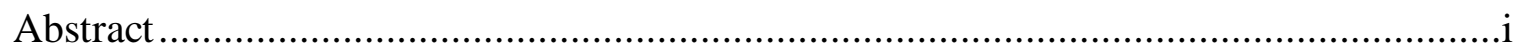

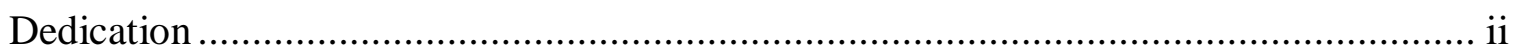

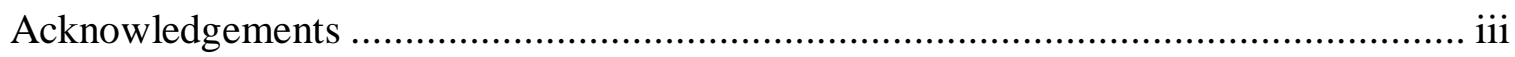

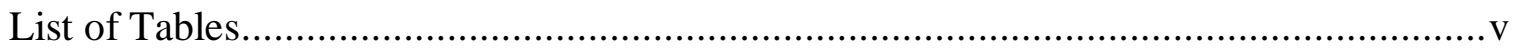

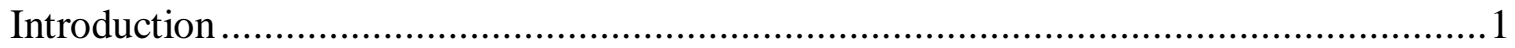

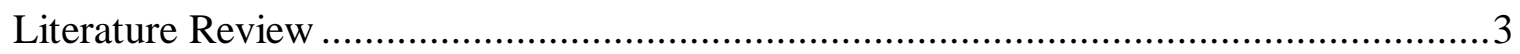

Correctional Quackery and Programs ............................................................

Intermediate Outcomes .....................................................................4

Misconduct in Correctional Facilities ........................................................6

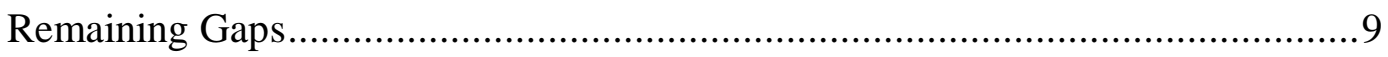

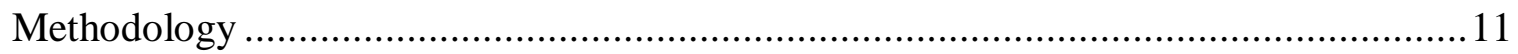

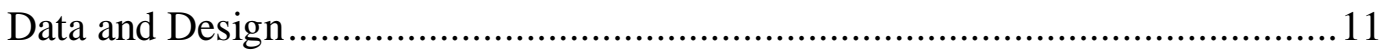

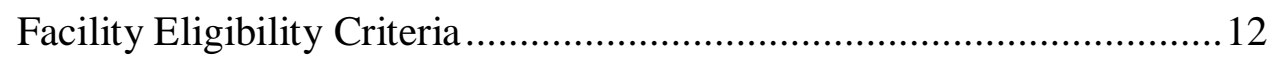

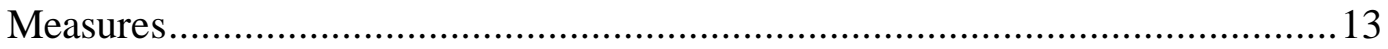

Dependent Variables ................................................................. 13

Independent Variables ............................................................. 13

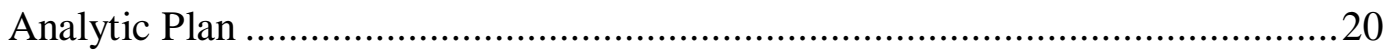

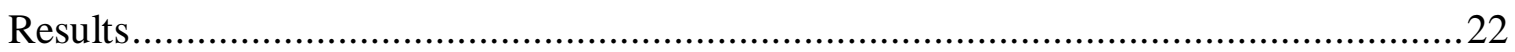

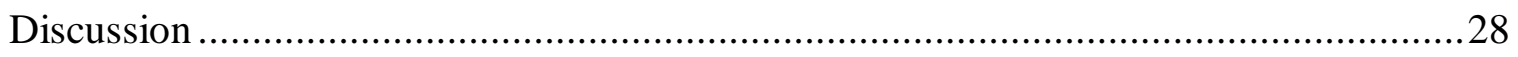

Limitations and Future Research.................................................................... 33

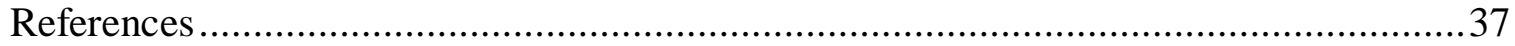

Appendix A - Primary Independent Variables .............................................. 43

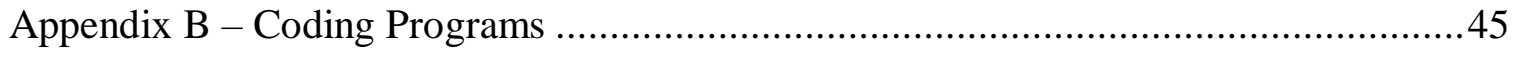




\section{List of Tables}

Table 1. Coding schemes and sources for primary independent variables .....................16

Table 2. Descriptive statistics for dependent and independent measures...................... 19

Table 3. Negative binomial regression analysis summary ......................................26 


\section{Introduction}

According to the Bureau of Justice Statistics' report on U.S. prisoners in 2017, the population of incarcerated individuals is the lowest it has been in almost 20 years (Bronson \& Carson, 2019). While this decrease marks an improvement, correctional facilities have also seen an enormous increase in rates of violent assault. In 2015 alone, there were almost 25,000 allegations of sexual violence in adult facilities; a 63\% increase from 2011 (Rantala, 2018). Of the substantiated incidents, more than half were found to have been committed by other inmates. For correctional facilities, the safety of staff and inmates is of utmost importance and immediate concern. Prior research has suggested a link between program availability and reducing violence in correctional facilities (Gaes \& McGuire, 1985; McCorkle, et al., 1995; Randol \& Campbell, 2017; Steiner \& Wooldredge, 2019). Therefore, implementation of adequate programs is significant not only for post-release impacts, but on inmate behaviors during incarceration as well.

Despite the existence of hundreds of programs, the utility of many have incited debate about the value of correctional programs and whether or not they "work." In correctional literature, the primary measurement of the success of a program is its impact on the reduction of recidivism. Many scholars believe these empirically supported programs that reduce reoffending are the only programs worthy of implementation in correctional facilities. Correctional programs that are not linked to decreasing recidivism via empirical findings have been deemed by some scholars as "correctional quackery" (Gendreau, Smith, \& Thériault, 2009). Such a label suggests that the legitimacy of these programs should be questioned as they may have the potential to do more harm than good. 
While reductions in reoffending are undoubtedly important and necessary, this solitary measurement does not consider secondary or intermediate outcomes that may have additional valuable impacts. Subsequently, others argue that the attribution of this solitary measurement narrows the scope of program utility. They suggest that additional benefits support the inclusion of alternative programs in the correctional environment. While there is validity to the concerns raised by quackery proponents, dismissing correctional programs that do not reduce recidivism could prevent other benefits such as behavioral changes (e.g., institutional misconduct), feelings of fulfillment, and prosocial attitudes (Lee \& Stohr, 2012).

As this debate continues, it is important to note that aspects of quackery programming have yet to be adequately tested by examining the effects of such programs in comparison to those that would not be deemed as quackery. This study considers program availability in 449 state correctional facilities, over three waves of data collection from 1995, 2000, and 2005 and examines the associated rates of inmate-on-inmate violent assaults in an effort to address this debate over program utility. The following sections will further elaborate on this dispute, apply theory to misconduct in correctional facilities, and summarize the findings of Randol and Campbell's (2017) preliminary research on the topic of inmate violence and program availability. 


\section{Literature Review}

\section{Correctional quackery and programming}

In criminology and correctional literature there lacks a consistent perspective of the utility of correctional programs; some scholars perceive particular programs as "quackery" while others suggest alternate uses. This debate questions whether or not programs that are not empirically shown to reduce recidivism have utility in the correctional setting. Gendreau, Smith, and Thériault (2009) argue that there is a strict distinction between programs that have value (i.e., evidence-based practices that reduce recidivism) and those that do not, which they term "correctional quackery." From their perspective, programs that fall into the correctional quackery category have no place in the criminal justice system as they waste resources and are manifestations of "bad common sense." These "common sense" programs are often derived from personal experience and require no training, education, or research. Gendreau et al. (2009) note an example of a program stemming from personal experience from 1994 about the continued use of boot camps in Georgia despite a lack of evidence. Regardless of the absence of empirical data supporting boot camps, the ex-Marine governor's own positive experiences with bootcamps persuaded him to perceive them as a "common sense" solution. In his eyes, if boot camps provided benefits

for himself, then they certainly could help delinquent Americans. However, the lack of supporting empirical data, particularly for correctional populations, indicates that boot camps would not be an appropriate correctional program. Additional popular examples of correctional quackery programs include yoga, pet therapy/training, art, and literacy classes. 
Acknowledging that there exist some issues with programs that are rooted in popularity or the aforementioned "bad common sense", Lee and Stohr (2012) however, offer an opposition to the notion of correctional quackery. They propose that branching outside the rigid criminological structure encourages creative and collaborative possibilities. Essentially, they argue that recidivism should not be the only measurement of a worthwhile program. Decreased costs, mental and physical health benefits, and orderly facilities (i.e., reducing institutional misconduct) can also serve as important and meaningful measures. Such measures are understood as intermediate outcomes. Lee and Stohr (2012) note that intermediate outcomes such as learned coping mechanisms, life skills, physical health impacts, reduced stress levels, and experiences of belonging are all important for what some may call quality-of-life or stabilizing factors (Taxman \& Caudy, 2015). An integration of criminology with a multitude of other disciplines such as sociology and psychology encourage growth in alternative means to targeting criminogenic attitudes. While Gendreau et al. (2009) suggest that programs with no theoretical basis can have damaging implications, Lee and Stohr (2012) argue that programs based in theory outside the discipline of criminology can still have merit beyond recidivism rates.

\section{Intermediate Outcomes}

A multitude of research studying impacts of individual "correctional quackery" programs have found positive outcomes outside the traditional measurement of recidivism. Three studies about rescue dog training programs in correctional settings found that inmates experienced empathy, calmness, better moods, self-reflection, stress relief, and the ability to better process emotions (Cooke \& Farrington, 2016; Smith, 2019; Smith \& Smith, 
2019). These measurements are not directly related to recidivism but they mark human growth and trajectory toward prosocial attitudes that improve quality of life.

Similarly, research examining yoga and meditation in correctional facilities found that it not only gave inmates "something to do" but it also reduced stress and depression while increasing self-esteem, and improved sleep (Auty, Cope, \& Liebling, 2017; Bartels, Oxman, \& Hopkins, 2019). While the practice of yoga may not directly result in reduced reoffenses, the short-term intermediate outcomes can benefit an inmates physical and mental health. In another study, working in HIV peer classes were found to be correlated with lower misconduct rates (Collica-Cox, 2014). The researchers noted that the overall involvement and desire to continue working in the program motivated positive behavioral conduct.

These examples highlight only a small subset of "correctional quackery" programing and some of their positive intermediate outcomes. There are many other programs including, but not limited to horticulture grounds maintenance, art classes, religious groups, and book clubs that have additional measurements of success. These alternative positive outcomes foster prosocial attitudes that are likely to have a spillover affect into aspects of life outside correctional facilities. Most important for justice officials, is safety. As a result, the measurement of infractions will be discussed subsequently as a possible alternative, or intermediate outcome.

Intermediate outcomes are perhaps most apparent in correctional institutions as they often take the form of misconduct or rule infractions. Influencing the frequency of misconduct, particularly violent misconduct, has been recently examined empirically. In 
2017, Randol and Campbell studied factors within 487 state and federal correctional facilities and their correlation with rates of inmate-inmate and inmate-staff violence. One of the factors they consider is the relationship of available correctional programs and the instances of these inmate assaults. While they found an association between broadly defined programming availability and reduced inmate-inmate assaults, the only program negatively associated with inmate-staff assaults was farming and agriculture. Horticulture, like farming and agriculture, is one of the classic examples Gendreau and colleagues (2009) reference as correctional quackery.

\section{Misconduct in Correctional Facilities}

Depending on the lens through which inmate misconduct is considered, there are three primary theories that can be used to explain predictors for these infractions: importation, situational, and deprivation theory. Importation theory emphasizes that an inmate's pre-existing individual characteristics and history are central to predicting behavior while incarcerated (Hochstetler \& DeLisi, 2005; Irwin \& Cressey, 1962; Jiang \& Fisher-Giorlando, 2002). For example, inmates with extensive criminal histories and issues with self-control, anger, and antisocial attitudes are predicted to have a greater number of incidents of misconduct. Instead of focusing on the characteristics of individuals, situational theory attributes infractions to reactions to the dynamic features of the facility's environment (Endler \& Magnussun, 1976; Jiang \& Fisher-Giorlando, 2002). These features can include crowding, staff and inmate characteristics, and the rigidity of a facility's surveillance. Finally, deprivation theory states that the strict rules, limited freedoms and privileges, and high stakes environment in correctional facilities create strain 
and tension among inmates that make it difficult to adapt to life in prison and result in misconduct (Hochstetler \& DeLisi, 2005; McCorkle, Miethe, \& Drass 1995; Sykes, 1958).

Jiang and Fisher-Giorlando (2002) look at these three models to examine their effectiveness in the explanation of incidents of violence among inmates and upon staff. Their study used data from a Southern men's state prison and three variables looking at violent versus non-violent misconduct, misconduct against staff, and misconduct against inmates in reference to each of the three theoretical models. Several of the variables indicating the situational model include correctional officer race, their years of education, and the racial composition and differences in education between officers and inmates. For the importation model, variables include characteristics and behaviors of inmates such as their race, age, education level, conviction history, and relationship status. Finally, deprivation indicators include sentence length, length of time served, and type of housing unit. Jiang and Fisher-Giorlando found that the dependent variable which focuses on incidents between inmates indicated that the situational and importation models better explain these occurrences (2002). However, findings indicated that all three models were significant in explaining violent incidents in general. It is important to note that while the deprivation model was not considered the best model for inmate-inmate violent offenses, this study does not consider the availability of programs as an indicator of deprivation. Therefore, the study's lack of support specifically for inmate-inmate violence and deprivation theory still warrants further investigation.

In their study of inmates at a midwestern, male correctional facility, Hochstetler and DeLisi (2005) examined infractions and their associations with deprivation and 
importation theory measurements. For measures of importation, Hochstetler and DeLisi questioned inmates to assess their antisocial attitudes, self-control, and anger management in addition to prior prison offenses. One of the deprivation measurements considered an individual's involvement in the "inmate economy," which refers to the transactions of prohibited goods and services in exchange for money or other possessions in prison. Questions about an inmate's substance use, loaning of goods, and payment for services such as chores while incarcerated were used to create a measurement of an inmate's participation in the inmate economy (Hochstetler \& DeLisi, 2005). The involvement in the inmate economy illustrates the pressure to act out as a result of strict limitations and desire to have access to forbidden items (Hochstetler \& DeLisi, 2005). Not only are these activities and their exchange criminogenic, but their lack of positive, pro-social, influences creates tension that encourage conflict. Hochstetler and DeLisi (2005) found that the measurement for inmate economy was highly predictive of misconduct as it encourages a system of haves and have nots. This specialized economy fosters stress through a constant craving of goods and activities that in other contexts, may not have been restricted. Likewise, a limited offering of programs leaves little opportunities for prosocial interactions and activities outside the rigid correctional routine. Similar to the defiant inmate economy, the restricted (or deprived) freedoms of life while incarcerated creates stress and tension that, given no positive outlet, may escalate and be expressed through physical and sexual violence with other inmates.

Although the complexities and interrelated causes for misconduct can be explained through a combination of the three theories, the current study will demonstrate that a focus 
of program availability and its relation to violent assaults among inmates is best illustrated by the deprivation model. Offering a variety of programs can help mediate the stress and tensions from rigid limitations and promote a degree of normalcy. I argue that wide availability of correctional programs allows for inmates to engage in activities that allow a semblance of freedom and agency and motivate pro-social, positive, behaviors that reduces violent assaults.

In their 2017 research mentioned above, Randol and Campbell identified associations between program availability and inmate violence using the same Census data as this current study. Their results for inmate-on-inmate violence indicated support for deprivation theory as the general availability of programs was associated with a reduction of violent assaults among inmates. Results from the panel data analysis of the three waves of data showed that half of the program groupings were significant predictors of decreased inmate-inmate assaults. Specifically, were programs addressing substance abuse, sex offenders, family and life skills, and education.

\section{Remaining gaps}

While Randol and Campbell's (2017) variables for correctional programs were broadly categorized by type (e.g., educational programs or cognitive behavioral treatment), they were not aiming to distinguish between correctional quackery and evidence-based programming. There have been numerous qualitative studies that provide individual support for correctional quackery programs such as yoga and dog training (Auty, Cope, \& Liebling, 2017; Bartels, Oxman, \& Hopkins, 2019; Collica-Cox, 2014; Cooke \& Farrington, 2016; Smith, 2019; Smith \& Smith, 2019). And many more empirically 
supported studies for programs that reduce recidivism (Aos, Miller, \& Drake, 2006; Drake, 2007; Lipsey, Landenberger, \& Wilson, 2007; Wanner, 2018). In spite of Randol and Campbell's and these prior studies, attention has not yet been given to the combined consideration of the dispute in utility of correctional quackery programs and correlations to inmate violence. Therefore, this study aims to address some of the elements of the correctional quackery debate in efforts to expand the perception of success beyond a single outcome and encourage further research into the value of intermediate outcomes of alternative programs. 


\section{Methodology}

The current study expands on Randol and Campbell's 2017 research through an alternative categorization of available correctional programs that speaks to the debate of utility in "correctional quackery" programming. Specifically, this study separates the effects of those programs that meet the definition of correctional quackery (which will be defined in subsequent sections) and those that do not. This extension of Randol and Campbell's study includes a secondary analysis of the same state and federal correctional data, although refines the focus by only considering violent assault rates between inmates at facilities with available programs coded as correctional quackery, and those that are rooted in evidence-based practice. This research aims to answer the question: What is the impact of "correctional quackery" program on the number availability of assaults among inmates in the correctional setting, as opposed to those programs that have been empirically supported? Given the debate on correctional quackery and its utility, and the lack of evidence connecting quackery programs to misconduct outcomes in prison, the hypothesis for this study is the null:

Hypothesis: The existence of programs defined as correctional quackery will result in similar rates of inmate-inmate assaults as the availability of programs that do not meet the definition of correctional quackery.

\section{Data and Design}

This study uses data from the Bureau of Justice Statistics 1995, 2000, and 2005 Census of State and Federal Adult Correctional Facilities. These data sets include information such as facility demographics, populations, conditions, assaults, and treatment programs provided in the facilities. 


\section{Facility Eligibility Criteria}

The data sets from the Census of State and Federal Adult Correctional Facilities used in this research contained a variety of facilities with an initial 1,500 facilities in 1995, 1,668 in 2000 , and 1,821 for 2005. Depending on the type of facility, as noted by Randol and Campbell (2017), there may be distinct structural and cultural differences between facilities due to differences in the housed populations, many of which would skew the findings. As a result, any facility that were specific to youthful offenders, juveniles, women, or housed both men and women from all data sets were not eligible to be a part of this study and subsequently removed from the data. In addition, any facilities noted as temporary housing, work camps, halfway houses, pre-trial facilities, rehab centers, community corrections, or conservation camps were also eliminated as they did not meet the criteria of target population. This left several hundred correctional facilities housing solely male inmates: 670 facilities in 1995, 649 in 2000, and 723 in 2005.

The three respective data sets span across ten years and many facilities were not listed in all three due to closures or lack of reporting for that year. In addition, other facilities may have been counted separately in some years, combined in others, listed under a different name, or changed their primary function. Data regarding the location of the facility in combination with its name were used to research and ensure accurate matching of facilities across the years. Therefore, the sample was further reduced to include only the remaining male correctional facilities that were reported across all three Census years leaving 449 state correctional facilities. 


\section{Measures}

\section{Dependent Variables}

In correctional facilities maintaining safety and order for staff and inmates are of the upmost importance. Therefore, measurements considering infractions, particularly violent assaults, would be the most meaningful method of examining potential intermediate outcomes of program availability. Specifically, the outcome measure used in this study is the total number of violent physical or sexual assaults by inmates upon other inmates.

Initial research methodology by the Bureau of Justice Statistics included a measure of the total number of these same forms of violent assaults by inmates on correctional staff. However, a significant portion (270) of facilities had missing observations of these counts in the 2005 Census that would have severely reduced the sample size. Therefore, this research focuses solely on the total violent assaults between inmates.

\section{Independent Variables}

Within the field of criminology and criminal justice there does not exist a standard definition of what correctional quackery entails. Using pertinent literature related to coding treatment programs (Gendreau, Smith, \& Thériault, 2009; Latessa, Cullen, \& Gendreau, 2002; Lee \& Stohr, 2012; Campbell et al., 2019) I was able to formulate a cohesive description and definitive coding system as to whether or not a particular program is “quackery.” Gendreau et al.'s (2009) primary contention with programs deemed to be quackery is that they are not empirically supported to reduce recidivism. Additionally, they criticize a lack of theoretical foundation for these types of correctional programs. Latessa et al. state, "Correctional quackery, therefore, is the use of treatment interventions that are 
based on neither 1) existing knowledge of the causes of crime nor 2) existing knowledge of what programs have been shown to change offender behavior" (2002, p. 43).

Lee and Stohr (2012), while less critical of "common sense" correctional programs, qualify quackery as lacking in empirical research specifically on the intended population. Therefore, when coding programs offered by facilities as correctional quackery or not, I used the following chart derived from a similar coding methodology that can be found in Campbell, Makin, and Rijkhoff (2016) for distinguishing between punitive or progressive rhetoric.

Table 1 provides a breakdown of how correctional quackery and non-quackery were coded. The common categorization of correctional quackery is conceptualized in dichotomous terms: A program is either empirically supported, reduces recidivism, is based in theory, and follows the eight principles of effective correctional intervention, or it is correctional quackery. Specifically, regarding the debate however, is the question of reduction of recidivism or not. Therefore, distinguishing the programs in this data set as correctional quackery or not will follow this strict delineation. It is important that each of these variables is dichotomous and measures correctional quackery versus all else or not correctional quackery or all else. Appendix A provides a breakdown of these variables.

The census survey used to compile the data included several questions that asked the facilities to identify which, if any, programs their facility offered. Following this, was an option to write in programs if facilities felt that none of the options given adequately represented a program or programs that they provided. While many facilities did indicate the offering of some of the pre-written options, a majority of the programs listed in the data 
came from the survey's specify option. In 1995's reduced data set there were 123 programs noted between the 449 facilities, out of these about $87 \%$ had been written in as the "specify" option. Similarly, 2000 had $89 \%$ and $200588 \%$ of all programs were specified in this writein space. This high percentage of written in specified programs indicates the necessity of reliance on identified program names in order to categorize them into programs that meet the definition of correctional quackery and those that do not (see Table 1).

The aforementioned definition for correctional quackery was used to classify programs into categories of correctional quackery or not correctional quackery. In addition, each of the programs were grouped into the following variables: education, employment, mental health, substance abuse, vocational, and other. A variable for each of these (one as correctional quackery, another as not correctional quackery) make up the twelve primary independent variables. Each of these twelve variables are dichotomous and measure programs that are correctional quackery (1) and everything else (0). Refer to the appendix B for detailed examples of program categorization per these delineations.

Although prison work assignments and work furloughs are not necessarily a program per se, I include them in the list of programming based on their inclusion in other research. Both Jung (2019) and Duwe (2018) evaluated programming and work releases within the correctional setting and measured them as programs. In addition, Washington State's inventory of evidence-based and research-based adult corrections programs categorizes prison work as a program when they conduct their evaluations (2018). Finally, 
Table 1. Coding schemes and sources for primary independent variables

\begin{tabular}{|c|c|c|}
\hline Code & Source & Components \\
\hline \multirow{3}{*}{$\begin{array}{l}\text { Correctional } \\
\text { Quackery }\end{array}$} & $\begin{array}{l}\text { Gendreau, Smith, \& } \\
\text { Thériault (2009) }\end{array}$ & $\begin{array}{l}\text { - No evidence of recidivism reduction } \\
\text {-Lacks theoretical basis }\end{array}$ \\
\hline & $\begin{array}{l}\text { Lee and Stohr } \\
(2012)\end{array}$ & $\begin{array}{l}\text { - Not empirically supported in correctional setting } \\
\text { - "Faddish" and popularity } \\
\text { - Measurements other than reductions in recidivism }\end{array}$ \\
\hline & $\begin{array}{l}\text { Campbell, Abboud, } \\
\text { Hamilton, } \\
\text { vanWormer, \& } \\
\text { Posey (2019) }\end{array}$ & $\begin{array}{l}\text { - Evaluated as research-based, promising practice, or } \\
\text { consensus-based ranking (as opposed to evidence-based) } \\
\text { - Not empirically tested with rigor, no reduction in } \\
\text { recidivism, does not follow the principles of effective } \\
\text { correctional intervention (see Latessa et al. 2002) }\end{array}$ \\
\hline \multirow{4}{*}{$\begin{array}{l}\text { Evidence- } \\
\text { Based } \\
\text { Programing } \\
\text { (Not } \\
\text { correctional } \\
\text { quackery) }\end{array}$} & $\begin{array}{l}\text { Gendreau, Smith \& } \\
\text { Thériault (2009) }\end{array}$ & $\begin{array}{l}\text { - Evidence-based and empirically supported with random } \\
\text { control trials } \\
\text { - Based in theory }\end{array}$ \\
\hline & $\begin{array}{l}\text { Lee and Stohr } \\
\text { (2012) }\end{array}$ & -Evidence of reduction in recidivism \\
\hline & $\begin{array}{l}\text { Campbell, Abboud, } \\
\text { Hamilton, } \\
\text { vanWormer, \& } \\
\text { Posey (2019) }\end{array}$ & $\begin{array}{l}\text { - Rigorous evaluation: more than one randomized or } \\
\text { statistically controlled study or one large multi side } \\
\text { randomized or statistically controlled study } \\
\text { - Reduction in recidivism } \\
\text { - Studied on population similar to one intended } \\
\text { - Program enacted using theory and past practice } \\
\text { - evidence based ranking }\end{array}$ \\
\hline & $\begin{array}{l}\text { Latessa, Cullen, \& } \\
\text { Gendreau (2002) }\end{array}$ & $\begin{array}{l}\text {-Eight principles of effective correctional intervention } \\
\text { 1. Organized } \\
\text { 2. Well-implemented } \\
\text { 3. Well-managed/staffed } \\
\text { 4. Client RNR } \\
\text { 5. Program characteristics (CBT, target criminogenic } \\
\text { factors) } \\
\text { 6. Core correctional practice (problem-solving, cognitive } \\
\text { self-change) } \\
\text { 7. Inter-agency communication } \\
\text { 8. Routine evaluation }\end{array}$ \\
\hline
\end{tabular}


the Bureau of Justice Statistics Census of State and Federal Adult Correctional Facilities data included prison employment under the category of programs, therefore I have continued with this categorization.

It is also important to note the categorization of work programs as correctional quackery. While work assignments and work releases may in fact be employment during incarceration, these jobs do not necessarily result in direct employment upon release and if they do, they have not been conclusively linked to reducing recidivism (Bohmert \& Duwe, 2011; Maguire, Flanagan, \& Thornberry, 1988; Drake, 2007; Duwe, 2014). Generally, these work programs are found to be research based which categorizes them into correctional quackery as they do not meet the strict evidence-based metrics.

In addition to these program measurements, six other variables associated with inmate misconduct in are included in the analysis. The ratio of correctional staff to inmate population in a facility has been shown to have a significant impact on the rates of violent misconduct (Steiner, 2009; McCorkle, Miethe, \& Drass, 1995). A greater ratio of correctional staff to inmate populations increases the ability to adequately supervise inmates and may deter them from engaging in behaviors due to the perception of a greater likelihood of apprehension. Using the original 1995, 2000, and 2005 census data's variables for total correctional staff and total inmate population I computed a new variable to represent their ratio.

Previous studies have indicated that the racial make-up of correctional populations is correlated with the rates of assault. In particular, higher proportions of African American inmates have been correlated with increased levels of violent assault (Steiner, 2009). 
Steiner's cross-sectional study of the same 1995 and 2000 Census data used in this study, found mixed results regarding the relationship between the proportion of Hispanic inmates and rates of assault. However, with this growing racial population within United States correctional facilities the growing diversity in an already tense correctional climate can foster dissension. A theory attributed as a potential explanation for these correlations and frictions include Samson and Grove's (1989) updated social disorganization theory where the high concentrations of ethnic and racial heterogeneity creates barriers and obstacles to social cohesion (Steiner, 2009). As with the to staff-inmate ratio, original variables provided in the Census data for population of Hispanic inmates and population of African American inmates were divided by the total inmate population for the creation of each of their proportion measurements.

Research on the impacts of prison crowding and rates of violence have also often found a positive relationship, noting issues of personal space and conflict over resources (Gaes, 1994; Gaes \& McGuire, 1985). Crowding and availability of programs in a facility could indicate a significant overlap if there are a lack of programs and limiting restrictions causing frustration and leaving more time for potentially delinquent behaviors. However, it is also important to note that other studies have found no support or mixed findings for the impact of crowding on violence in correctional facilities (Wooldredge \& Steiner, 2009; Glazener \& Nakamura, 2020). Variances in these findings do not necessarily indicate a lack of correlation between crowding and inmate violence. As previously indicated, nuanced differences between facilities such as resource availability and staff to inmate ratios likely impact the outcomes for these findings. The data's dichotomous $(0=$ no, $1=y e s)$ 
Table 2: Descriptive statistics for dependent and independent measures

\begin{tabular}{|c|c|c|c|}
\hline Measures & 1995 & 2000 & 2005 \\
\hline \multicolumn{4}{|l|}{ Dependent variable } \\
\hline Inmate-inmate assaults & $30.51(65.77)$ & $28.72(59.53)$ & $21.52(44.013)$ \\
\hline \multicolumn{4}{|l|}{ Independent variables } \\
\hline Crowding & $21.60 \%$ & $8.69 \%$ & $4.01 \%$ \\
\hline $\begin{array}{l}\text { Proportion inmates African } \\
\text { American }\end{array}$ & $0.50(0.21)$ & $0.47(0.21)$ & $0.45(0.19)$ \\
\hline Proportion inmates Hispanic & $0.09(0.13)$ & $0.09(0.12)$ & $0.12(0.13)$ \\
\hline $\begin{array}{l}\text { Ratio correctional officers to } \\
\text { inmates }\end{array}$ & $0.25(0.12)$ & $0.25(0.11)$ & $0.23(0.14)$ \\
\hline $\begin{array}{l}\text { Proportion inmates maximum } \\
\text { security }\end{array}$ & $0.19(0.30)$ & $0.17(0.29)$ & $0.19(0.30)$ \\
\hline $\begin{array}{l}\text { Proportion inmates minimum } \\
\text { security }\end{array}$ & $0.42(0.39)$ & $0.42(0.42)$ & $0.43(0.40)$ \\
\hline \multicolumn{4}{|l|}{$\begin{array}{l}\text { Facility programs-Correctional } \\
\text { quackery }\end{array}$} \\
\hline Substance abuse & $96.43 \%$ & $94.43 \%$ & $79.29 \%$ \\
\hline Mental health & $83.74 \%$ & $75.72 \%$ & $69.93 \%$ \\
\hline Vocational & $0.89 \%$ & $6.90 \%$ & $0.67 \%$ \\
\hline Educational & $0.22 \%$ & $0.45 \%$ & $1.78 \%$ \\
\hline Employment & $99.78 \%$ & $99.78 \%$ & $99.55 \%$ \\
\hline Other & $17.37 \%$ & $99.55 \%$ & $99.11 \%$ \\
\hline \multicolumn{4}{|l|}{ Facility programs-Not quackery } \\
\hline Substance abuse & $0.45 \%$ & $0.67 \%$ & $0.45 \%$ \\
\hline Mental health & $1.11 \%$ & $2.67 \%$ & $4.45 \%$ \\
\hline Vocational & $77.28 \%$ & $7.13 \%$ & $70.38 \%$ \\
\hline Educational & $95.99 \%$ & $96.21 \%$ & $93.32 \%$ \\
\hline Employment & $62.81 \%$ & $60.58 \%$ & $75.95 \%$ \\
\hline Other & $16.48 \%$ & $0.22 \%$ & $1.56 \%$ \\
\hline
\end{tabular}

Notes: Standard deviations are listed in parentheses. $N=449$. 
variable for crowding is provided in all three data sets. A correctional facility's crowding measurement comes from the population density: a facility's daily average population divided by its design capacity.

Finally, analysis includes measurements of the proportion of facilities whose inmates are in minimum security as well as a variable for the proportion of inmates in maximum security. As inmates whom are in maximum security have already engaged in some form of extreme misconduct to be placed in maximum security, it is not unreasonable to assume that it will happen again. In addition, those in maximum security have already received sanctions and a loss of privileges that may result in a reduction of motivations for having nothing to lose. Conversely, inmates in minimum security could be deterred by the potential loss of privileges. Therefore, results are expected to indicate a greater rate of violent assaults in facilities with a high proportion of inmates in maximum security. The

number of inmates in minimum and maximum security divided by the total inmate population provided the variable for their respective proportions.

\section{Analytical Plan}

Due to the highly skewed nature of the dependent measure (counts of assault between inmates) this study relies on a negative binomial regression to examine at the relationship between program availability and incidents of violent assaults among inmates. A model was conducted for each of the three census years' data and each produced a McFadden's pseudo R-squared. Within each year's model the variables' incidence rates 
were recorded and used to interpret the expected rate of assaults. Coefficients and Rsquared values were then compared to interpret any change from year to year. 


\section{Results}

Supporting prior research, it is unsurprising to see that for all three census data years the ratio of staff to inmate, proportion of inmates in minimum security, and proportion inmates in maximum security have significant associations with the incidence rate of assaults inflicted by inmates on other inmates (Steiner, 2009). Increases in the proportion of maximum security inmates were associated with an increase in assaults among inmates. Conversely, increases in the number of correctional staff in relation to the total inmate population as well as increased percentages of minimum security inmates were associated with a decrease in assaults among inmates.

Results from Table 3 indicate that the availability of correctional quackery programs or those not meeting the definition of correctional quackery yielded mixed findings regarding rates of assaults among inmates. However, the fairly equal dispersion of the few significant variables between both categories of programs fails to reject the null hypothesis.

First, there are several programs that indicate an increase in incidence rate for violent assaults among inmates. In 1995, facilities with mental health programs that meet the definition for correctional quackery are associated with $64 \%(\mathrm{IRR}=1.64, p=0.003)$ more assaults between inmates than facilities without these programs. Mental health programs meeting the definition for correctional quackery were also associated with greater counts of assaults among inmates in 2000 as well; an incidence rate of assaults almost three $(\mathrm{IRR}=2.94, p<0.001)$ times that of facilities without these programs. The only other correctional quackery program subtype associated with larger counts of assaults is 
vocational at almost three times greater than facilities without vocational programs that meet the definition for correctional quackery.

In addition, there are also several program subtypes which do not meet the definition of correctional quackery that are also associated with greater counts of inmateon-inmate assaults: vocational, educational, and employment. In 1995 vocational programs that do not meet the definition for correctional quackery are associated with $64 \%$ more assaults between inmates than facilities without these programs. 1995's dataset also found that facilities with educational programs that do not meet the definition for correctional quackery have an incidence rate of more than twice ( $I R R=2.21, p=0.031)$ as many assaults among inmates that facilities without non-correctional quackery educational programs. These same programs are also associated with an increase in the 2005 dataset as well; an incidence rate of a little over five ( $\mathrm{IRR}=5.08, p<0.001)$ times as many inmate assaults as facilities without these programs. Finally, the dataset from 2000 found that facilities that offered employment programs which do not meet the definition for correctional quackery were associated with $84 \%$ more assaults than facilities without them.

There are three programs however, that were significantly associated with a decrease in incidence rate for inmate-on-inmate assaults after all other covariates were held constant; all from the 2005 Census years' data. First, facilities that provide mental health programs that do not meet the definition of correctional quackery are associated with $62 \%$ $(\mathrm{IRR}=0.28, p<.001)$ less assaults between inmates than correctional centers without these programs. All of these mental health programs that were coded into this program type included some form of Cognitive Behavioral Therapy. CBT is a well-established evidence- 
based intervention that addresses distorted thinking patterns for those in the general population as well as individuals in correctional facilities. The psychological roots of CBT not only function to address criminogenic thinking, but also general mental well-being (Lipsey, Landenberger, \& Wilson, 2007). The targeting of thought processes assists in problem solving and anger control both of which, while not changing the situation itself, allow for an individual to change the way they perceive events. Mental health programs that meet the definition of correctional quackery may have elements of improving aspects of mental health, but lack of focus on teaching skills for changing detrimental thought patterns. Therefore, mental health programs that do not meet the definition of correctional quackery support previous studies regarding the significance of Cognitive Behavioral Therapy. And subsequently, the intermediate effects on decreased incidence rates of assaults among inmates.

In addition to mental health, in the 2005 dataset sample, facilities with employment programs that do not meet the definition of correctional quackery are associated with $28 \%$ (IRR $=0.72, p=0.027)$ less inmate-on-inmate assaults than correctional facilities without these programs. Employment programs in this category include the given option of "employment" on the Census survey as well as programs that provide employment counseling and preparation. Offering opportunities for employment as well as training for job success after release, provides a source of motivation. Inmates involved in these programs likely have a desire to acquire legal employment and are encouraged to have a pro-social and law-abiding lifestyle. While still incarcerated, these motivations may 
produce secondary outcomes of positive behaviors that influence lower rates of violent assaults than facilities without these programs.

Finally, the only program measurement that demonstrated a decreased incidence rate in violent assaults among inmates and also meets the definition of correctional quackery is substance abuse. Results from the 2005 dataset indicate that facilities with these substance abuse programs are associated with $42 \%$ (IRR $=0.58, p=0.000$ ) less violent assaults than facilities without. Many of the substance abuse programs coded into correctional quackery were linked with religious components or were education-based. While these programs and methods may not have evidence of reducing recidivism, the encouragement of pro-social behaviors of religious involvement can reduce incidents of assault among inmates (Kerley, Matthews, \& Blanchard, 2005). Therefore, despite their lack of Cognitive Behavioral elements or strict treatment elements, the availability of substance abuse programs that would be categorized as correctional quackery may have secondary outcomes.

It is important to note that all three of the program categories that suggested an association with a decrease in assaults among inmates were found in the 2005 Census years' data (Non-correctional quackery mental health, non-correctional quackery employment, and correctional quackery substance abuse programs). This is supported by the higher McFadden's pseudo r-squared for 2005's data indicating that this model better predicts the outcomes. The growing body of literature and knowledge regarding correctional programs over the past few decades suggest that program qualities are improving and there is an elimination of those failing to produce positive outcomes. 
Table 3. Negative Binomial Regression Analysis Summary

\begin{tabular}{|c|c|c|c|c|c|c|c|c|c|}
\hline & \multicolumn{3}{|c|}{1995} & \multicolumn{3}{|c|}{2000} & \multicolumn{3}{|c|}{2005} \\
\hline Independent Variables & IRR & {$[95 \% \mathrm{CI}]$} & $p$ & IRR & {$[95 \% \mathrm{CI}]$} & $p$ & IRR & {$[95 \% \mathrm{CI}]$} & $p$ \\
\hline Crowding & .95 & {$[.74-1.23]$} & .716 & .78 & {$[.54-1.12]$} & .179 & 1.10 & {$[.64-1.89]$} & .732 \\
\hline Proportion inmates African American & 1.41 & {$[.84-2.38]$} & .198 & .88 & {$[.54-1.44]$} & .600 & 1.32 & {$[.70-2.47]$} & .388 \\
\hline Proportion inmates Hispanic & 1.22 & {$[.50-3.01]$} & .664 & 2.02 & {$[.84-4.84]$} & .119 & .91 & {$[.03-.26]$} & $<.001$ \\
\hline Ratio correctional staff to inmates & .04 & {$[.01-.10]$} & $<.001$ & .03 & {$[.01-.08]$} & $<.001$ & .03 & {$[.01-.09]$} & $<.001$ \\
\hline Proportion inmates in maximum security & 1.74 & {$[1.11-2.73]$} & .015 & 4.14 & {$[2.56-6.68]$} & $<.001$ & 4.95 & {$[3.06-8.00]$} & $<.001$ \\
\hline Proportion inmates in minimum security & .14 & {$[.10-.19]$} & $<.001$ & .18 & {$[.13-.25]$} & $<.001$ & .40 & {$[.29-.55]$} & $<.001$ \\
\hline Correctional quackery programs & & & & & & & & & \\
\hline Substance abuse & 1.30 & {$[.74-2.27]$} & .360 & 1.13 & {$[.68-1.87]$} & .631 & .58 & {$[.43-.78]$} & $<.001$ \\
\hline Mental health & 1.64 & {$[1.18-2.28]$} & .003 & 2.94 & {$[2.22-3.89]$} & $<.001$ & 1.29 & {$[.96-1.72]$} & .088 \\
\hline Vocational & 2.95 & [1.06-8.23] & .038 & 1.50 & [.19-11.89] & .701 & .35 & {$[.07-1.83]$} & .216 \\
\hline Educational & 4.59 & {$[.63-33.52]$} & .133 & .37 & {$[.09-1.58]$} & .179 & .44 & {$[.14-1.34]$} & .146 \\
\hline
\end{tabular}




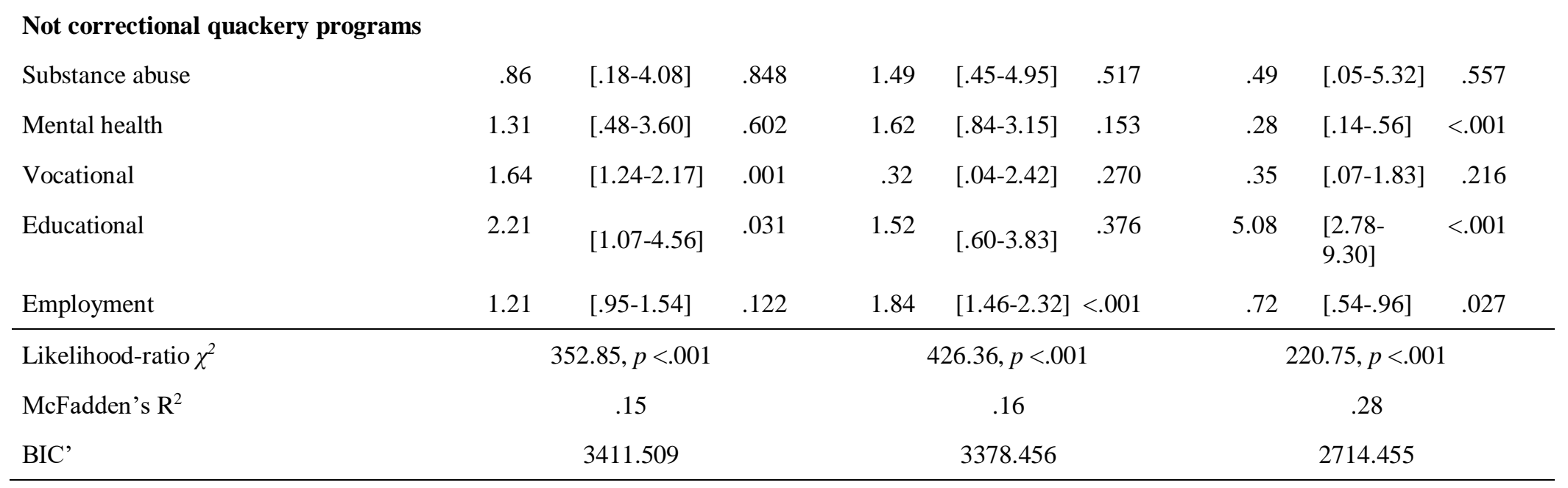




\section{Discussion}

The minimal significant associations for program availability and inmate-oninmate assaults yields inconclusive findings for the support of general program availability. For many programs in all three Census years, quackery or otherwise, the availability of the programs is associated with an increase in inmate-on-inmate assault. It is important to consider, however, that the availability of programs not only increases gatherings, but also the heterogenic interaction of inmates who may not otherwise have associated (Sampson \& Groves, 1989). A greater frequency of diverse inmates coming into contact with each other for the purpose of a program or activity, regardless the type, is likely to increase tensions and strains. These tensions stemming from not only the general heterogeneity of the participants, but the correctional culture is likely to increase rates of assaults.

As an alternative to the higher frequency of associated decreases in the 2005 dataset, most of the associated decreases can be found in the 1995 dataset. It is possible that knowledge and studies examining the relationship of correctional programs and incidents of assaults was still being developed and honed. Therefore, it is understandable to see greater frequencies of assaults among inmates in association with programs in earlier years where there may have been less of a robust understanding of what programs influenced positive behaviors over negative ones. In addition, around this time there was still emphasis on incapacitation and punishment over rehabilitation which may have driven resources away from these rehabilitative programs. These 1995 programs associated with an increase are correctional quackery mental health and vocational as well as noncorrectional quackery vocational and education. The greater count of assaults among 
inmates associated with both vocational programs that do and do not meet the definition for correctional quackery in 1995 is an interesting outcome. As many other program categories also offer a wide variety of offerings indicating a high concentration of heterogeneric participants, the strains from this density is unlikely to be sole reason for the associated incidents of assaults. Therefore, there may have been other factors occurring within these types of programs that correlate with assaults.

Another interesting outcome is the high incidence rate ratio (IRR=5.08) from the 2005 dataset for educational programs that do not meet the definition for correctional quackery. In 2005 while about $85 \%$ of correctional facilities offered education classes only about a third offered college level programs and 165 had no educational classes (Stephan, 2008). With such low availability of these programs and market expectations of college level education, it's possible that the higher incidence rate of assaults between inmates at facilities with these programs is a manifestation of the deprivation model. The limited resources and availability for higher education may create tensions and difficulty adapting that become expressed through physical assault.

In addition, Randol and Campbell (2017) noted similar associated increases in assault with several types of programs. They indicate that it is important to consider that for none of the program types (e.g. educational, substance abuse, mental health) was the primary goal to reduce misconduct in correctional facilities. Therefore, the lack of significant results indicating decreases in violent assaults does not necessarily imply failed support for the availability of various programs. Instead, this prompts further research and a panel analysis which could indicate decreases in the increased assaults over time. 
Alternatively, with minimal information regarding the specifics of programs and the combination of correctional Risk Needs Responsivity (RNR) model, it is possible that these increases could be an illustration of the deprivation model. The RNR principles assert that for best rehabilitative results, focus should be placed on individuals whom pose the greatest risk, by addressing their criminogenic needs, and doing so through appropriate treatment methods (Andrews, Bonta, \& Hoge, 1990). The lack of details about programs and their implementation in the Census data provides no information as to whom they may available. Per the RNR model, many may only be open to the subset of inmates in the higher risk category. This potential restriction of programs for higher risk inmates may inadvertently create tensions among other inmates who are limited in their program choices. The perceived deprivation of resources and opportunities paired with the rigidity of incarcerated life and minimal personal freedoms may translate into misconduct and increases in violent assault.

It is also relevant to note that over the past several decades, the quality of correctional programs has increased as implementation is assessed and best practices components are observed. Regular processes evaluations and research on a program's implementation has increased transparency and accountability, and reduced the divide between researchers and practitioners (Miller \& Miller, 2015). The continual assessment of programs along with a growing body of knowledge for best practices fosters a better understanding between correctional staff and researchers (Latessa, 2004). This improvement in the frequency and methodology of program evaluations encourages 
assessments that can provide support for programs that are adhere to best practices that subsequently impact rates of violence.

The three program categories indicating an associated decrease in assaults are likely reflective of the forms of programs coded into those categories. For example, all programs in the non-correctional quackery mental health category have some form of Cognitive Behavioral Therapy elements. CBT, as previously stated, is an empirically-supported treatment that addresses root causes of distorted thinking that can assist in the development of problem-solving. The availability of programs implementing these strategies may not only impact those involved, but other inmates they come into contact with. Increasing the ability to think through conflicts and decrease impulsivity may allow that individuals to step away from situations that have the potential to escalate and prevent a violent incident.

The second program that is with a decrease in assaults among inmates is noncorrectional quackery employment. Programs coded into this category included opportunities for current employment as well as counseling and employment preparation. The deprivation model suggests that conflict and stress from an inability to adapt to a new normal, life in a correctional facility, can escalate to misconduct and assault (Hochstetler \& DeLisi, 2005). However, the opportunity for employment may provide a sense of normalcy and stability that negates some of the adaptation difficulties. Furthermore, career and employment preparation suggest that a degree of hope exists for prospects beyond the strict routines; whether than indicates employment post-release or a position with the facility during their sentence. The privilege of these opportunities creates motivation to 
maintain positive behaviors and could influence the associated decrease in assaults among inmates.

The third program category is the only significant correctional quackery program to show an associated decrease in assaults among inmates: substance abuse programs. While the substance abuse programs in the correctional quackery category lack empirically supported treatment methods and CBT components, they still provide an opportunity for interaction outside the rigid routines of correctional facilities. Many of these programs are faith based and support-oriented as opposed to more strict components of other substance abuse treatment programs. An opportunity to engage in these supportive interactions that lack the formality of other treatment may be more appealing to a greater number of inmates. In addition, the prosocial interactions through support and faith may decrease stressors and subsequently help an inmate adapt to life while incarcerated. This mediation of tensions and stress supports the notion that a wide availability of programs could help address violence and assaults stemming from feelings of deprivation. 


\section{Limitations and Future research}

A key limitation to this research is the self-reporting of program availability by the facilities. Without detailed information regarding each program it is possible that names seem to not meet the definition of correctional quackery, but in reality, are not actually adequately evidence-based in practice. Latessa, Cullen, \& Gendreau (2002) describe eight key principles of effective correctional intervention; therefore, it is possible that while a reported program name indicates an evidence-based program (therefore not correctional quackery) it may not meet the standards in its implementation.

However, when coding programs as correctional quackery or not, I took a conservative approach and only noted them as not correctional quackery if the reported program title indicated an evidence-based approach (i.e. the phrase Cognitive Behavioral Intervention). For any uncertainty, research into the program according to its reported name generally indicated the appropriate category. All other programs that could not be coded as not correctional quackery per the strict delineation, were classified into their respective correctional quackery program category. Therefore, the strict definition of the types of programs that are considered to not be correctional quackery created a clear division between the two categories.

Even with an elimination of many correctional facilities that did not meet the study criteria, there still exists variety in the size of the facilities. On the smaller end there were some facilities with a population of inmates of only double digits while some of the larger facilities had several thousand inmates. Despite these vast differences in inmate population, I chose not to include facility population as a variable as corrections literature has not found 
significant links between population and assaults. While a location may have a large population of inmates, they likely also have a greater square footage. Therefore, variables that have been found to impact misconduct such as the density or crowding of facilities were included as they indicate tensions from proximity and insufficient resources (Steiner \& Wooldredge, 2009).

Initial research plans included an outcome variable for assaults inflicted by inmates on facility staff. However, a significant portion of these counts were missing from the data and made the inclusion of this outcome variable unsuitable for this research. A replication of this research with this data included could yield valuable results regarding similarities and difference between program availability and rates of violent misconduct.

Due to the skewed distribution of inmate-on-inmate assaults, a negative binomial regression was the appropriate statistical tool to use. However, this method also requires the use of a dependent variable that measures count. In not using the rate of assaults among inmates instead of the count, the data does not account for inmate assaults in relation to the inmate population. The inclusion of a crowding measurement as mentioned above however, has been shown to have more significance in relation to assaults than the actual population size.

In addition, transforming the dichotomous independent variables for programs into trichotomous would allow for a deeper analysis of differences between program availability. This measurement would allow the comparison of incidence rate of assaults between facilities with only a correctional quackery type of program as opposed to a facility without a program of that type. Would facilities with these correctional quackery 
programs have rates indicating that something is better than nothing? Or might findings indicate a greater harm and wasted resources? Transforming the independent variable in this way could consider facilities that offer either program distinction (correctional quackery or not), both, or neither program.

Also, the inclusion of a measure considering the number of programs at each facility would be a beneficial in order to consider the ratio of program availability to the population of inmates at a facility. This could provide additional information regarding the deprivation theory and access to particular resources while incarcerated.

The intention of this research was to use cross-sectional data to examine if a relationship existed between program availability and inmate-on-inmate assaults and if it existed, was it positive or negative. Despite the absence of statistical analysis to consider potential causality, this study indicates a need for further research that could investigate possible causal relationships through methods such as paneled, pooled time-series.

The use of this macro-level data allowed for a wide scope of programing availability at the national level and can be beneficial for indicating programs that warrant additional research. Future research considering the nuances of meso- and micro-level analyses could yield other measurements that could have an impact on the program influence. For example, details regarding a correctional inmate's motivations and reasons for involvement in particular programs may provide valuable measures for further examination of intermediate outcomes of a variety of programs. The programs listed in the Census survey or written in by staff, give no detailed information regarding the details of inmate involvement. For instance, what limitations prevent an inmate from involvement, 
what, if any, incentives are offered? Future research examining differences in programs defined as correctional quackery or not would benefit from a consideration of nuances such as this.

Although the Census of State and Federal Adult Correctional Facilities is conducted every five years, the most recent available data was from 2005. Currently, the Bureau of Justice Statistics has limited variables for the 2012 data and access is not yet available for the 2019 data. When these datasets become available, the difference of almost ten or fifteen years could demonstrate substantial changes in not only program availability but the demographics of facilities. Future research should continue to examine additional years as the Census data becomes available to continue exploring the intermediate outcomes of correctional programs.

This analysis and research encourage a consideration of only a portion of potential benefits of correctional programs outside of recidivism reduction. While reducing likelihood of reoffending is a key goal of correctional systems, the possibility for other positive outcomes should not be so quickly dismissed. Continued measurements of alternative intermediate outcomes such as mood, stress, empathy, and feelings of fulfillment could challenge the traditional "recidivism-reduction or bust" and expand notions of what is considered correctional success. 


\section{References}

Allen, L. C., MacKenzie, D. L., \& Hickman, L. J. (2001). The effectiveness of Cognitive Behavioral Treatment for adult offenders: A methodological, quality-based review. International Journal of Offender Therapy and Comparative Criminology, 45(4), 498-514. https://doi.org/10.1177\%2F0306624X01454009

Andrews, D. A., Bonta, J. \& Hoge, R. D. (1990). Classification for effective rehabilitation: Rediscovering psychology. Criminal Justice and Behavior, 17, 1952. https://doi.org/10.1177\%2F0093854890017001004

Aos, S., Miller, M., \& Drake, E. (2006). Evidence-based adult corrections programs: What works and what does not. (no. 06-01-1201). Olympia, WA: Washington State Institute for Public Policy. http://www.wsipp.wa.gov/ReportFile/924

Aos, S., Phipps, P., Barnoski, R., \& Lieb, R. (2001). Evidence-based adult corrections programs: What works and what does not. (no. 06-01-1201). Olympia, WA: Washington State Institute for Public Policy. http://www.wsipp.wa.gov/ReportFile/924

Auty, K. M., Cope, A., \& Liebling, A. (2017). A systematic review and meta-analysis of yoga and mindfulness meditation in prison. International Journal of Offender Therapy \& Comparative Criminology, 61(6), 689-710. https://doi.org/10.1177/0306624X15602514

Bartels, L., Oxman, L. N., \& Hopkins, A. (2019). "I would just feel really relaxed and at peace": Findings from a pilot prison yoga program in Australia. International Journal of Offender Therapy and Comparative Criminology, 63(15-16), 25312549. https://doi.org/10.1177/0306624X19854869

Batchelder, J. S., \& Pippert, J. M. (2002). Hard time or idle time: factors affecting inmate choices between participation in prison work and education programs. The Prison Journal, 82(2), 269-280. https://doi.org/10.1177/003288550208200206

Blinn, C. (1995). Teaching cognitive skills to effect behavioral change through a writing program. Journal of Correctional Education, 46(4), 146-154. https://www.jstor.org/stable/23294087?seq=1\&cid=pdfreference\#references_tab_contents

Bohmert, M. N. \& Duwe, G. (2011). Minnesota's affordable homes program: Evaluating the effects of a prison work program on recidivism, employment and cost avoidance. Criminal Justice Policy Review, 23(3), 327-351. https://doi.org/10.1177/0887411411911 
Bronson, J. \& Carson, E. A. (April 2019). Prisoners in 2017. U.S. Department of Justice, Bureau of Justice Statistics, NCJ 252156. Retrieved from:

http://www.bjs.gov/index.cfm?ty=pbdetail\&iid=6546

Campbell, C. M., Abboud, M. J., Hamilton, Z. K., vanWormer, J., \& Posey, B. (2019). Evidence-based or just promising? Lessons learned in taking inventory of state correctional programming. Justice Evaluation Journal, 1(2), 188-214. https://doi.org/10.1080/24751979.2018.1528849

Campbell, C. M., Makin, D. A., \& Rijkhoff, S. A. (2017). A rhetorical balancing act: Popular punitivism in the Netherlands. Punishment \& Society, 19(5), 543567.https://doi.org/10.1177/1462474516672882

Chappell, C. A. (2004). Post-secondary correctional education and recidivism: A metaanalysis of research conducted 1990-1999. Journal of Correctional Education, 55(2), 148-169. www.jstor.org/stable/23292162

Collica-Cox, K. (2014). Counting down: HIV prison-based peer education programs and their connection to reduced disciplinary infractions. International Journal of Offender Therapy \& Comparative Criminology, 58(8), 931-952. https://doi.org/10.1177/0306624X13490660

Cooke, B. J., \& Farrington, D. P. (2016). The effectiveness of dog-training programs in prison: A systematic review and meta-analysis of the literature. The Prison Journal, 96(6), 854-876. https://doi.org/10.1177/0032885516671919

Drake, E. (2007). Does Participation in Washington's Work Release Facilities Reduce Recidivism?. (Report no. 07-11-1201). Olympia, WA: Washington State Institute for Public Policy.

Drake, E. (2013). Inventory of evidence-based and research-based programs for adult corrections. (Report no. 13-12-1901). Olympia, WA: Washington State Institute for Public Policy.

Duwe, G. (2014). An outcome evaluation of a prison work release program: Estimating its effects on recidivism, employment, and cost avoidance. Criminal Justice Policy Review, 26(6), 531-554. https://doi.org/10.1177/0887403414524590

Duwe, G. (2017). The use and impact of correctional programming for inmates on preand post-release outcomes. Washington DC: National Institute of Justice. Retrieved from: https://www.ncjrs.gov/pdffiles1/nij/250476.pdf 
Duwe, G. (2018) The effects of the timing and dosage of correctional programming on recidivism. Journal of Offender Rehabilitation, 57(3-4), 256-271.

https://doi.org/10.1080/10509674.2017.1401025

Erisman, W. \& Contardo, J. B. (2005). Learning to reduce recidivism: A 50-state analysis of postsecondary correctional education policy. The Institute for Higher Education Policy. https://eric.ed.gov/?id=ED558210

Ferguson, L. M. \& Wormith, J. S. (2012). A meta-analysis of Moral Reconation Therapy. International Journal of Offender Therapy and Comparative Criminology, 57(9), 1076-1106. https://doi.org/10.1177\%2F0306624X12447771

Gaes, G. G. (1994). Prison crowding research reexamined. The Prison Journal, 74(3), 329-363. https://doi.org/10.1177/0032855594074003004

Gaes, G. G. \& McGuire, W. J. (1985). Prison violence: The contribution of crowding versus other determinants of prison assault rates. Journal of Research in Crime and Delinquency, 22(1), 41-65. https://doi.org/10.1177/0022427885022001003

Gendreau, P., Smith, P., \& Thériault, Y. L. (2009). Chaos theory and correctional treatment: Common sense, correctional quackery, and the law of fartcatchers. Journal of Contemporary Criminal Justice, 25(4), 384-396. https://doi.org/10.1177/1043986209344552

Glazner, E. \& Nakamura, K. (2020). Examining the link between prison crowding and inmate misconduct: Evidence from prison-level panel data. Justice Quarterly 37(1), 109-131. https://doi.org/10.1080/07418825.2018.1495251

Hall, L. L. (2015). Correctional education and recidivism: Toward a tool for reduction. Journal of Correctional Education, 66(2), 4-29. www.jstor.org/stable/26507655

Hochstetler, A. \& DeLisi, M. (2005). Importation, deprivation, and varieties of serving time: An integrated-lifestyle-exposure model of prison offending. Journal of Criminal Justice, 33, 257-266. doi:10.1016/j.jcrimjus.2005.02.005

Jiang, S. \& Fisher-Giorlando, M. (2002). Inmate misconduct: A test of the deprivation, importation, and situational models. The Prison Journal, 82(3), 335-358. https://doi.org/10.1177\%2F003288550208200303

Jung, H., \& LaLonde, R. J. (2019). Prison work-release programs and incarcerated women's labor market outcomes. The Prison Journal, 99(5), 535-558. https://doi.org/10.1177/0032885519875009 
Kerley, K. R., Matthews, T. L., \& Blanchard, T. C. (2005). Religiosity, religious participation, and negative prison behaviors. Journal for the Scientific Study of Religion, 44(4), 443-457. https://doi.org/10.1111/j.1468-5906.2005.00296.x

Latessa, E. T., Cullen, F. T., \& Gendreau, P. (2002). Beyond correctional quackery-professionalism and the possibility of effective treatment. Federal Probation, 66(2), 43.

Lee, L. C., \& Stohr, M. K. (2012). A critique and qualified defense of "correctional quackery." Journal of Contemporary Criminal Justice, 28(1), 96-112. https://doi.org/10.1177/1043986211432203

Little, G. L. (2006). Review of one-to three-year recidivism of felony offenders treated with MRT @ in prison settings. Cognitive Behavioral Treatment Review, 15(1). 13. https://nicic.gov/review-one-three-year-recidivism-felony-offenders-treatedmrt-prison-settings-2006

Little, G. L., Robinson, K. D., Burnette, K. D., \& Swan, E. S. (2010). Twenty-year recidivism results for MRT-treated offenders: A preliminary analysis. Journal of Community Corrections, 19(3-4). https://www.moral-reconationtherapy.com/Resources/2010-Journal_of_Community_Corrections.pdf

Lipsey, M. W., Landenberger, N .A., \& Wilson, S. J. (2007). Effects of cognitivebehavioral programs for criminal offenders. Campbell Systematic Reviews, 6. https://doi.org/10.4073/csr.2007.6

Maguire, K. E., Flanagan, T. J., \& Thornberry, T. P. (1988). Prison labor and recidivism. Journal of Quantitative Criminology, 4(1), 3-18. https://doi.org/10.1007/BF01066881

McCorkle, R. C., Miethe, T. D., \& Drass, K. A. (1995). The roots of prison violence: A test of deprivation, management, and "not-so-total" institution models. Crime \& Delinquency, 41(3), 317-331. https://doi.org/10.1177/0011128795041003003

Miller, J. M. \& Miller, H. V. (2015). Rethinking program fidelity for criminal justice. Criminology and Public Policy, 14(2), 339-349. https://doi.org/10.1111/1745$\underline{9133.12138}$

National Institute of Corrections. (2007). Cognitive-Behavioral Treatment: A review and discussion for corrections professionals. https://nicic.gov/cognitive-behavioraltreatment-review-and-discussion-corrections-professionals

Office of Justice Programs. All programs \& practices. Retrieved February, 4, 2020. From CrimeSolutions.gov 
Pearson, F. S., Lipton, D. S., Cleland, C. M., \& Yee, D. S. (2002). The effects of Behavioral/Cognitive-Behavioral programs on recidivism. Crime and Delinquency, 48(3), 476-496. https://doi.org/10.1177\%2F001112870204800306

Randol, B. M., \& Campbell, C. M. (2017). Macro-correlates of inmate violence: The importance of programming in prison order. The Prison Journal, 97(4), 451-474. https://doi.org/10.1177/0032885517711975

Rantala, R. R. (July 2018). Sexual victimization reported by adult correctional authorities, 2012-15. U.S Department of Justice, Bureau of Justice Statistics, NCJ 251146. Retrieved from http://www.bjs.gov/index.cfm?ty=pbdetail\&iid=6326

Samenow, S. E. (1991). Correcting errors of thinking in the socialization of offenders. Journal of Correctional Education. 42(2), 56-58. https://www.jstor.org/stable/41970866

Sampson, R. J. \& Groves, W. B. (1989). Community structure and crime: Testing socialdisorganization theory. American Journal of Sociology, 94(4), 774-802. http://doi.org/10/1086/229068

Smith, H. P. (2019) A rescue dog program in two maximum-security prisons: A qualitative study, Journal of Offender Rehabilitation, 58(4), 305-326. http://doi.org/10.1080/10509674.2019.1596189

Smith, H. P., \& Smith, H. (2019). A qualitative assessment of a dog program for youth offenders in an adult prison. Public Health Nursing, 36(4), 507-513. https://doi.org/10.1111/phn.12622

Steiner, B. (2009). Assessing static and dynamic influences on inmate violence levels. Crime \& Delinquency, 55(1), 134-161. http://doi.org/10.1177/0011128707307218

Steiner, B. \& Wooldredge, J. (2019). Understanding and reducing prison violence: An integrated social control-opportunity perspective. Routledge.

Stephan, J. J. (2008). Census of State and Federal Correctional Facilities, 2005. Washington, DC: U.S. Department of Justice, Bureau of Justice Statistics.

United States Department of Justice. Office of Justice Programs. Bureau of Justice Statistics. Census of State and Federal Adult Correctional Facilities, 2005. Ann Arbor, MI: Inter-university Consortium for Political and Social Research [distributor], 2017-05-12. https://doi.org/10.3886/ICPSR24642.v3 
United States Department of Justice. Office of Justice Programs. Bureau of Justice Statistics. Census of State and Federal Adult Correctional Facilities, 2000. Ann Arbor, MI: Inter-university Consortium for Political and Social Research [distributor], 2005-11-04. https://doi.org/10.3886/ICPSR04021.v1

United States Department of Justice. Office of Justice Programs. Bureau of Justice Statistics. Census of State and Federal Adult Correctional Facilities, 1995. Ann Arbor, MI: Inter-university Consortium for Political and Social Research [distributor], 2003-03-21. https://doi.org/10.3886/ICPSR06953.v1

United States Department of Justice. Office of Justice Programs. Bureau of Justice Statistics. Census of State and Federal Adult Correctional Facilities, 1990. Ann Arbor, MI: Inter-university Consortium for Political and Social Research [distributor], 2001-12-21. https://doi.org/10.3886/ICPSR09908.v2

Wanner, P. (2018). Inventory of evidence-based, research-based, and promising programs for adult corrections. (Report no. 18-02-1901). Olymipa, WA: Washington State Institute for Public Policy.

Wooditch, A., Tang, L. L., Taxman, F. S., (2014). Which criminogenic need changes are most important in promoting desistance from crime and substance use?. Criminal Justice Behavior, 41(3), 276-299. https://doi.org/10.1177/0093854813503543

Wooldredge, J. \& Steiner, B. (2009). Comparing methods for examining relationships between prison crowding and inmate violence. Justice Quarterly, 26(4), 795-826. https://doi.org/10.1080/07418820802427841 
Appendix A - Primary Independent Variables

\begin{tabular}{l|l}
\multicolumn{2}{l}{ Dichotomous Correctional Quackery Program Categories } \\
\hline Variable & Values \\
\hline CQ Education & $\begin{array}{l}\text { 1=Facility has this type of correctional quackery program } \\
0=\text { All else* }\end{array}$ \\
\hline $\begin{array}{l}\text { CQ Mental } \\
\text { Health }\end{array}$ & $\begin{array}{l}\text { 1=Facility has this type of correctional quackery program } \\
0=\text { All else* }\end{array}$ \\
\hline CQ Employment & $\begin{array}{l}\text { 1=Facility has this type of correctional quackery program } \\
0=\text { All else* }\end{array}$ \\
\hline CQ Vocational & $\begin{array}{l}1=\text { Facility has this type of correctional quackery program } \\
0=\text { All else* }\end{array}$ \\
\hline CQ Substance & $\begin{array}{l}1=\text { Facility has this type of correctional quackery program } \\
0=\text { All else* }\end{array}$ \\
\hline CQ Other & $\begin{array}{l}1=\text { Facility has this type of correctional quackery program } \\
0=\text { All else* }\end{array}$ \\
\hline
\end{tabular}

*All else=Facility has no correctional quackery programs of this type and/or only has programs that do not meet the definition for correctional quackery. 
Dichotomous Not Correctional Quackery Program Categories

\begin{tabular}{|c|c|}
\hline Variable & Values \\
\hline $\begin{array}{l}\text { Not CQ } \\
\text { Education }\end{array}$ & $\begin{array}{l}1=\text { Facility has this type of program that does not meet the definition of } \\
\text { correctional quackery } \\
0=\text { All else* }\end{array}$ \\
\hline $\begin{array}{l}\text { Not CQ Mental } \\
\text { Health }\end{array}$ & $\begin{array}{l}1=\text { Facility has this type of program that does not meet the definition of } \\
\text { correctional quackery } \\
0=\text { All else* }\end{array}$ \\
\hline $\begin{array}{l}\text { Not CQ } \\
\text { Employment }\end{array}$ & $\begin{array}{l}1=\text { Facility has this type of program that does not meet the definition of } \\
\text { correctional quackery } \\
0=\text { All else* }\end{array}$ \\
\hline $\begin{array}{l}\text { Not CQ } \\
\text { Vocational }\end{array}$ & $\begin{array}{l}1=\text { Facility has this type of program that does not meet the definition of } \\
\text { correctional quackery } \\
0=\text { All else* }\end{array}$ \\
\hline $\begin{array}{l}\text { Not CQ } \\
\text { Substance }\end{array}$ & $\begin{array}{l}1=\text { Facility has this type of program that does not meet the definition of } \\
\text { correctional quackery } \\
0=\text { All else* }\end{array}$ \\
\hline Not CQ Other & $\begin{array}{l}1=\text { Facility has this type of program that does not meet the definition of } \\
\text { correctional quackery } \\
0=\text { All else* }\end{array}$ \\
\hline
\end{tabular}

*All else=Facility has no programs of this type that do NOT meet the definition of correctional quackery and/or only have programs that DO meet the definition for correctional quackery. 


\section{Appendix B - Coding Programs}

Cognitive Behavioral Therapy or CBT is a well-established evidence-based program that reduces recidivism among other benefits (Allen, MacKenzie, \& Hickman, 2001; Aos, Phipps, Barnoski \& Lieb, 2001; Pearson, Lipton, Cleland, \& Yee, 2002). However, it is important to note that there are some programs that go by a different name but still employ the techniques of CBT. Moral Reconation Therapy, Thinking for Change, and Aggression Replacement Training are three examples of name brand programs. All three employ CBT techniques and (National Institute of Corrections, 2007). Therefore, programs listed under their name brand that were unfamiliar required additional research to ensure that they met the qualifications for not correctional quackery: evidence of reductions in recidivism.

The following chart demonstrates several examples of programs that had been written in the space provided for "specify" on the census. This illustrates how I determined if a program met the definition for correctional quackery or not. 
1995 data "specify" written in program coding examples

\begin{tabular}{|c|c|c|}
\hline Program & $\begin{array}{l}\text { CQ or Not } \\
\text { CQ* }\end{array}$ & Reasoning \\
\hline $\begin{array}{l}\text { Health and } \\
\text { Wellness }\end{array}$ & CQ & $\begin{array}{l}\text { Regardless of positive physical and mental health benefits this } \\
\text { type of program does not have empirical evidence for } \\
\text { reducing recidivism. }\end{array}$ \\
\hline School & Not CQ & $\begin{array}{l}\text { School does not indicate possibilities for interpretation besides } \\
\text { educational classes such as GED and college courses. } \\
\text { Education has been empirically supported to reduce } \\
\text { recidivism. (Chappell, 2004; Erisman \& Contardo, 2005; Hall, } \\
\text { 2015) }\end{array}$ \\
\hline $\begin{array}{l}\text { Counseling on } \\
\text { Criminal } \\
\text { Personality }\end{array}$ & CQ & $\begin{array}{l}\text { Targeting criminogenic thinking for reduced recidivism has } \\
\text { only been empirically supported when CBT techniques are } \\
\text { used. Without CBT or cognitive behavior in the name, we } \\
\text { cannot be sure this program uses those techniques. Therefore, } \\
\text { with the conservative approach it is coded as correctional } \\
\text { quackery. }\end{array}$ \\
\hline $\begin{array}{l}\text { Moral } \\
\text { Reconation } \\
\text { Therapy (MRT) }\end{array}$ & Not CQ & $\begin{array}{l}\text { MRT is a version of CBT that has been empirically supported } \\
\text { to reduce recidivism. (Allen, MacKenzie, \& Hickman, 2001; } \\
\text { Ferguson \& Wormith, 2012; Little, 2006; Little, Robinson, } \\
\text { Burnette, \& Swan, 2010; National Institute of Corrections, } \\
\text { 2007) }\end{array}$ \\
\hline $\begin{array}{l}\text { Alcoholics } \\
\text { Anonymous } \\
\text { (AA) }\end{array}$ & CQ & $\begin{array}{l}\text { This is an evidence-based program that targets substance } \\
\text { abuse. However, it is not empirically supported to reduce } \\
\text { recidivism. }\end{array}$ \\
\hline $\begin{array}{l}\text { Anger } \\
\text { Replacement } \\
\text { Training (ART) }\end{array}$ & Not CQ & $\begin{array}{l}\text { ART is a "name brand" anger management program that } \\
\text { focuses on prosocial behaviors: action, affective/emotional, } \\
\text { and thought/values which reflects CBT techniques. (National } \\
\text { Institute of Corrections, 2007) }\end{array}$ \\
\hline $\begin{array}{l}\text { Anger } \\
\text { Management }\end{array}$ & CQ & $\begin{array}{l}\text { Anger management has only been shown to reduce recidivism } \\
\text { when the program employs CBT techniques. This written-in } \\
\text { program name gives no indication if it uses these techniques, } \\
\text { therefore, with the conservative approach, it is coded as } \\
\text { correctional quackery. }\end{array}$ \\
\hline
\end{tabular}

*Program meets definition for correctional quackery or does not meet definition for correctional quackery 